\title{
ЗАСТОСУВАННЯ РЕСУРСУ WOLFRAMALPHA ДЛЯ МАTEMАTИЧНОГО МОДЕЛЮВАННЯ ФАРМАКОКІНЕТИЧНИХ ПРОЦЕСІВ
}

\author{
А. С. Сверстюк, Н. О. Кравець, Д. В. Вакуленко \\ ДВНЗ "Тернопільський державний медичний університет \\ імені І. Я. Горбачевського МОЗ України"
}

\begin{abstract}
Використання сучасних новітніх технологій в процесі викладання вищої математики, комп'ютерних технологій у фармації сприяє фрормуванню вмінь та навичок роботи в умовах комп'ютерного середовища, створенню та вивченню математичних моделей різноманітних явищ та процесів, демонстрації застосування математичних методів та їх дослідження. У статті розглянуто переваги та недоліки застосування WolframAlpha у формуванні предметної математичної компетентності майбутніх фармацевтів.
\end{abstract}

Ключові слова: ресурс WolframAlpha, математичне моделювання фрармакокінетичних процесів.

\section{ПРИМЕНЕНИЕ РЕСУРСА WOLFRAMALPHA ДЛЯ MATEMATИЧЕСКОГО МОДЕЛИРОВАНИЯ ФАРМАКОКИНЕТИЧЕСКИХ ПРОЦЕССОВ}

\author{
А. С. Сверстюк, Н. О. Кравець, Д. В. Вакуленко \\ ДВНЗ "Тернопольский государственный медицинский университет \\ имени И. Я. Горбачевского МОЗ Украины"
}

\begin{abstract}
Использование современных новейших технологий в процессе преподавания курсов высшей математики, компьютерных технологий в фармации способствует формированию умений и навыков работы в условиях компьютерной среды, созданию и изучению математических моделей разнообразных явлений и процессов, демонстрации применения математических методов и их исследования. В статье рассмотрены преимущества и недостатки применения Wolframalpha в формировании предметной математической компетентности будущих фрармацевтов.
\end{abstract}

Ключевые слова: ресурс Wolframalpha, математическое моделирование фрармакокинетичних процессов.

\section{APPLICATION OF RESOURCE WOLFRAMALPHA FOR MATHEMATICAL DESIGN OF FARMAKOKINETIC PROCESSES}

\author{
A. S. Sverstyuk, N. O. Kravets, D. V. Vakulenko \\ SHEI "Ternopii State Medical University by I. Ya. Horbachevsky of MPH of Ukraine"
}

\begin{abstract}
Using information technologies in the process of teaching higher mathematics, information technologies in pharmacy helps to develop students creativethinking and better skills of work in a computer environment. It also provides the higher level of getting knowledge, helps to create and study mathematical models of different phenomena; shows how to use and research mathematical methods. The article deals with advantages and disadvantages of using WolframAlpha while forming mathematical competence of future pharmacists.
\end{abstract}

Key words: resource of Wolframalpha, mathematical design of farmakokinetic processes.

Вступ. Інтеграція у європейський освітній простір вимагає змін у системі підготовки спеціалістів фармацевтичної галузі, які передбачають впровадження у дидактичну практику сучасних форм і методів навчання, іноді нетрадиційних та неоднозначних, перебудови навчального процесу та діяльності викладача. Для цього впроваджуються перспективні моделі освіти, що базуються на широкому викорис- танні новітніх інформаційних технологій. Очевидно, що реформування освіти повинно проходити одночасно з реформуванням галузі охорони здоров'я в Україні.

В умовах сучасної інформатизації суспільства інформаційно-комунікативні технології та сервіси мережі Інтернет складають невід'ємну частину життя кожної людини. У системі фундаментальної підго-

(C) А. С. Сверстюк, Н. О. Кравець, Д. В. Вакуленко 
товки сучасного фармацевта основою розв'язання проблеми формування професійної компетентності та забезпечення професійної мобільності $є$ також і якісна математична підготовка. Вона дозволяє здійснювати прогнозування результатів своєї діяльності, розробляти стратегії пошуку шляхів і методів вирішення професійних завдань [1].

До професійної компетентності фармацевта належить вміння володіти методами математичного моделювання при розв'язанні прикладних задач. На даний момент, у зв'язку зі скороченням навчальних годин, що відводяться на вивчення у вищій школі математики, європейського стандарту комп'ютерної грамотності та статистики, виникає проблема навчання студентів застосуванню математичного апарату для розв'язання прикладних задач біологічного, хімічного та фармацевтичного змісту. Тому навички моделювання, перевірки гіпотез та пошуку інформації набувають більшого значення, ніж суто формальне вивчення навчального матеріалу [2].

Використання засобів математично-комп'ютерного моделювання дає можливість навчити студентів формулювати прикладну задачу, розв'язати іiі математичними методами за допомогою відповідного програмного забезпечення та інтерпретувати результат розв'язку до реальної ситуації. Це дозволяє розв'язувати складні задачі, уникаючи громіздких розрахунків, та представляти їх у вигляді зручної наочної графіки - презентацій та змістовних звітів.

Мета дослідження. Використання сучасних новітніх технологій у фармації для формування вмінь та навиків роботи в умовах комп'ютерного середовища. Застосування ресурсу WolframAlpha для вивчення математичних моделей фармакокінетичних процесів.

Матеріали та методи дослідження. На кафедрі медичної інформатики Тернопільського державного медичного університету імені І. Я. Горбачевського при вивченні предметів «Вища математика» для студентів 1 курсу та «Комп'ютерні технології у фармації» для студентів 4 курсу фармацевтичного факультету запропоновано ряд практичних занять, що базуються на вивченні методів системного аналізу. Вони передбачають дослідження хімічних реакцій першого та другого порядків, процесів розчинення лікарської речовини з таблетки та рідин в організмі людини. Метою його вивчення є оволодіння теорією математичного моделювання фармацевтичних процесів і методами їх дослідження.

Насамперед ці заняття дозволяють студентам інтегрувати вивчення таких дисциплін як фармакологія, клінічна фармація, фармакогнозія та біологія.
Особливою проблемою є вибір відповідного програмного забезпечення $[5,6]$.

Слід зазначити, що на початку викладання цієї дисципліни науковцями кафедри були розроблені власні системи комп'ютерного моделювання фармамакокінетичних процесів 3 використанням технологій Internet-програмування [7].

Проте, на сьогоднішній час є можливість використання програмного забезпечення спеціалізованого призначення. Найдоцільним ми вважаємо використання CAM (Computer Aided Modelling).

Одним 3 найпоширеніших та найпотужніших засобів CAM є Mathematica. Однак для іiі використання потрібен комп'ютерний клас, що складає додаткові труднощі у використанні. Сучасний студент повинен мати можливість працювати будь-де та будь-коли. Виконання цієї умови можливе при використанні мобільних телефонів з підключенням до мережі Інтернет.

У травні 2009 р. з'явився принципово новий ресурс математико-орієнтованого пошукового web-cepвicy - WolframAlpha. Засновником даного проекту став Стівен Вольфрам, що створив на базі системи комп'ютерної математики Matematica базу знань і набір обчислювальних алгоритмів (англ. computational knowledge engine). WolframAlpha інтегрує й надає доступ до відомостей про навколишній світ у числовому вимірі, і має великий потенціал для забезпечення онлайнової підтримки навчання математичних дисциплін.

Робота WolframAlpha заснована на обробці природної мови (поки що тільки англійської), великій бібліотеці алгоритмів і NKS-підході до формування відповідей на запити.

WolframAlpha звільняє користувача від проведення громіздких рутинних викладок, однотипних обчислень і дозволяє зосередитися безпосередньо на аналізі модельованого явища. Безсумнівною перевагою WolframAlpha є прекрасні графічні можливості, що дозволяє зробити наочними багато математичних понять і методів.

WolframAlpha не видає перелік посилань, за результатами запиту, а обчислює відповідь, грунтуючись на власній базі знань, яка містить дані з математики, фізики, астрономії, хімії, біології, медицини, історії, географії, політики, музики, кінематографії, а також інформацію про відомих людей та інтернет-сайти.

У вивченні математики WolframAlpha може бути застосована до таких розділів:

- елементарна математика: основні арифметичні операції, у тому числі можливість роботи з коренями; 
- властивості та операції, пов'язані 3 цілими та комплексними числами, математичні константи;

- побудова графіків функцій однієї та кількох змінних (на площині та в просторі), розв'язування рівнянь та систем рівнянь;

- розв'язування нерівностей та систем нерівностей, перетворення раціональних дробів, робота 3 поліномами;

- обчислення визначників, робота 3 матрицями;

- обчислення сум числових послідовностей, границь послідовностей, знаходження похідних та обчислення інтегралів (невизначених та визначених);

- геометрія на площині та в просторі;

- комбінаторика та теорія графів;

- оптимізація функцій;

- логіка та теорія множин (булеві функції та діаграми Венна);

- статистика та аналіз даних.

Питання та запити у WolfTamAlpha можна задавати у вільній формі, тобто так, як думає людина. Особливістю WolframAlpha $\epsilon$ те, що даний ресурс повертає наочну та повну відповідь, яка включає в себе досить багато інформації, що відноситься до запиту. До не менш важливих переваг сервісу WolframAlpha можна віднести:

- безкоштовність;

- використання з мобільного пристрою;

- візуалізація процесу покрокового виконання операцій;

- можливість одержання точних відповідей;

- перегляд кроків алгоритмів розв'язування (в окремих випадках).

Результати та їх обговорення. Використання WolframAlpha впроваджено на кафедрі медичної інформатики для дослідження фармакокінетичних моделей.

Фармакокінетичні моделі описують кінетику (зміну з часом) розподілення введених в організм ліків. Терапевтичний ефект препарату залежить від його концентрації в хворому органі (орган-мішень) i часу перебування в діючій концентрації.

Завданням фармацевта $\epsilon$ оптимальне призначення ліків, тобто вибір дози, шляху і періодичності введення, котрі забезпечували б достатній терапевтичний ефект при мінімальній побічній дії.

Побудова фармакокінетичної моделі допомагає в розв'язанні цієї задачі [8]. Методика введення препарату повинна бути суворо індивідуальною, тобто в моделі повинні фігурувати індивідуальні параметри хворого.
Розглянемо розв'язок диференціального рівняння (1), що описує зміну маси лікарської речовини в організмі з використанням ресурсу WolframAlpha.

$$
\frac{d m}{d t}=-k m
$$

Для цього потрібно завантажити ресурс WolframAlpha, можна за адресою http:// www.wolframalpha.com (рис. 1).

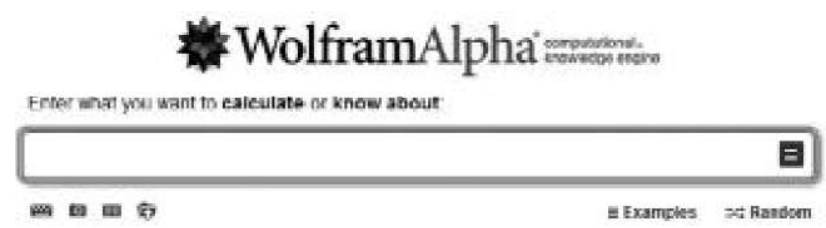

Puc. 1. Інтерфейс WolframAlpha.

Після завантаження WolframAlpha слід вибрати закладку "Examples", потім "CALCULUS \& ANALYSIS" та у комірку "Solve an ordinary differential equation" ввести диференціальне рівняння (1). Натиснувши на знак "=" отримаємо шуканий розв'язок (рис. 2).

У закладці "Differential equation solution" отримано загальний розв'язок диференціального рівняння (1) у вигляді:

$$
m(t)=c_{1} * e^{-k t}
$$

Загальний розв'язок диференціального рівняння (2) з урахуванням початкових умов: при $t=0$ маса введених лікарських препаратів $m=m_{0}$, має вигляд:

$$
m=m_{0} * e^{-k t}
$$

Для побудови графічної залежності кількості введених лікарських препаратів від часу задається незмінний коефіцієнт виведення препарату з організму $\mathrm{k}=0,1$ та різна початкова маса введених лікарських препаратів $\mathrm{m}_{01}=5 ; \mathrm{m}_{02}=9 ; \mathrm{m}_{03}=15$.

Використовуючи ресурс WolframAlpha у комірку "Solve an ordinary differential equation" потрібно ввести

plot $\mathrm{m}=5 * \exp (-0.1 * \mathrm{t}), \mathrm{m}=9 * \exp (-0.1 * \mathrm{t})$,

$\mathrm{m}=15 * \exp (-0.1 * \mathrm{t}), \mathrm{t}=0 \ldots 20$

Натиснувши на "=" отримаємо побудовані залежності кількості введених лікарських препаратів від часу (рис. 3).

При залученні WolframAlpha для обчислень потрібно пам'ятати, що використовувати обчислювальну систему не завжди просто. Для одних і тих же завдань система може пропонувати кілька варіантів виконання, і студент, який застосовує систему, повинен вміти вибрати найбільш ефективний. Будь-яка система комп'ютерної математики не застрахована 


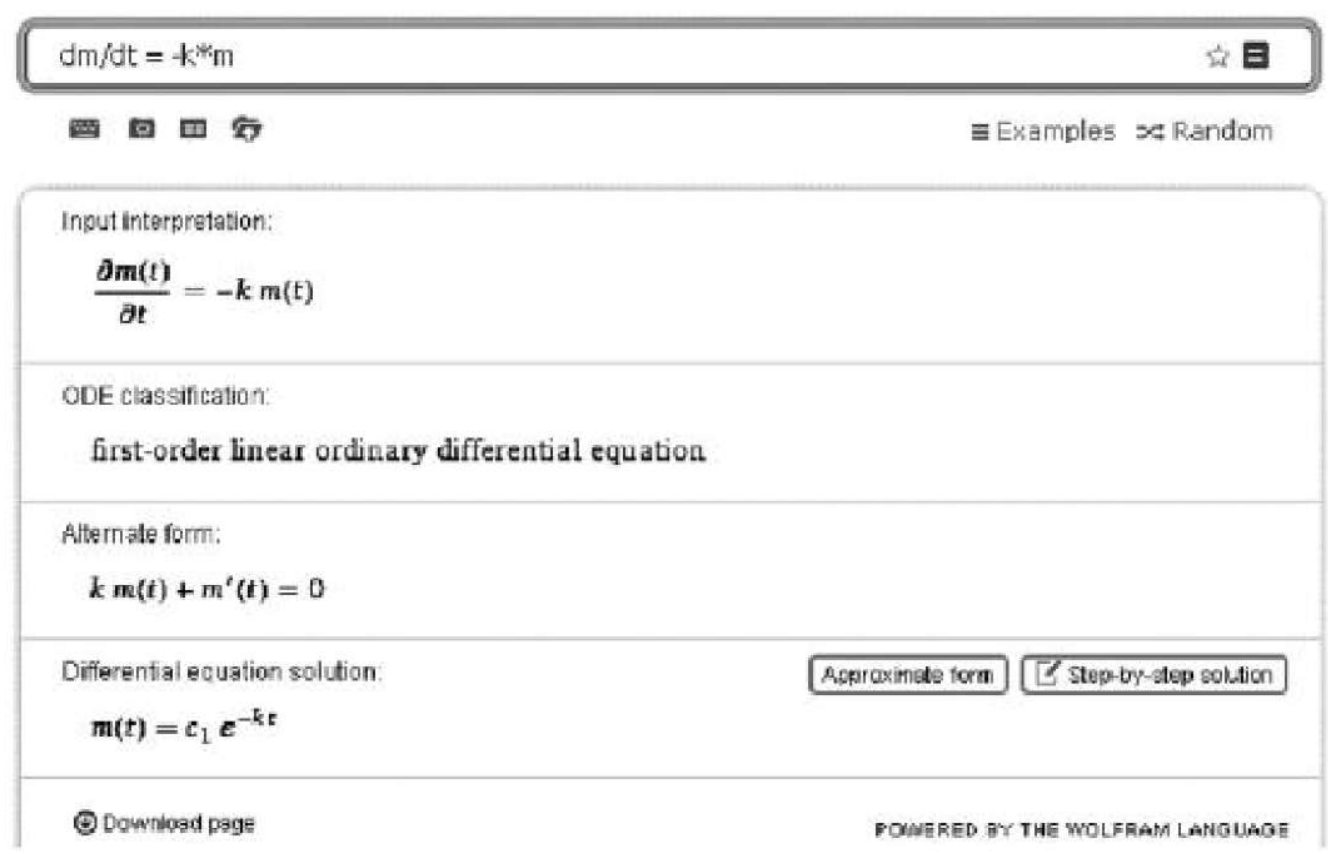

Puc. 2. Розв'язок диференціального рівняння моделі одноразового введення препарату в орган.

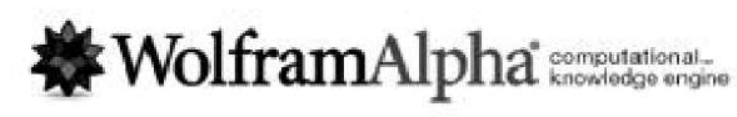

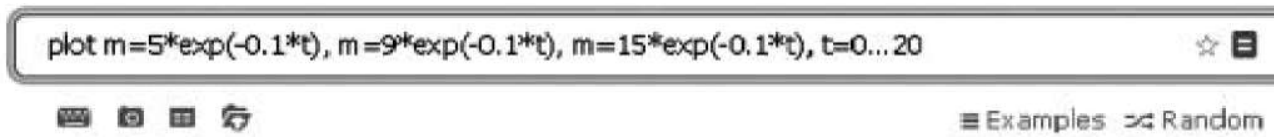

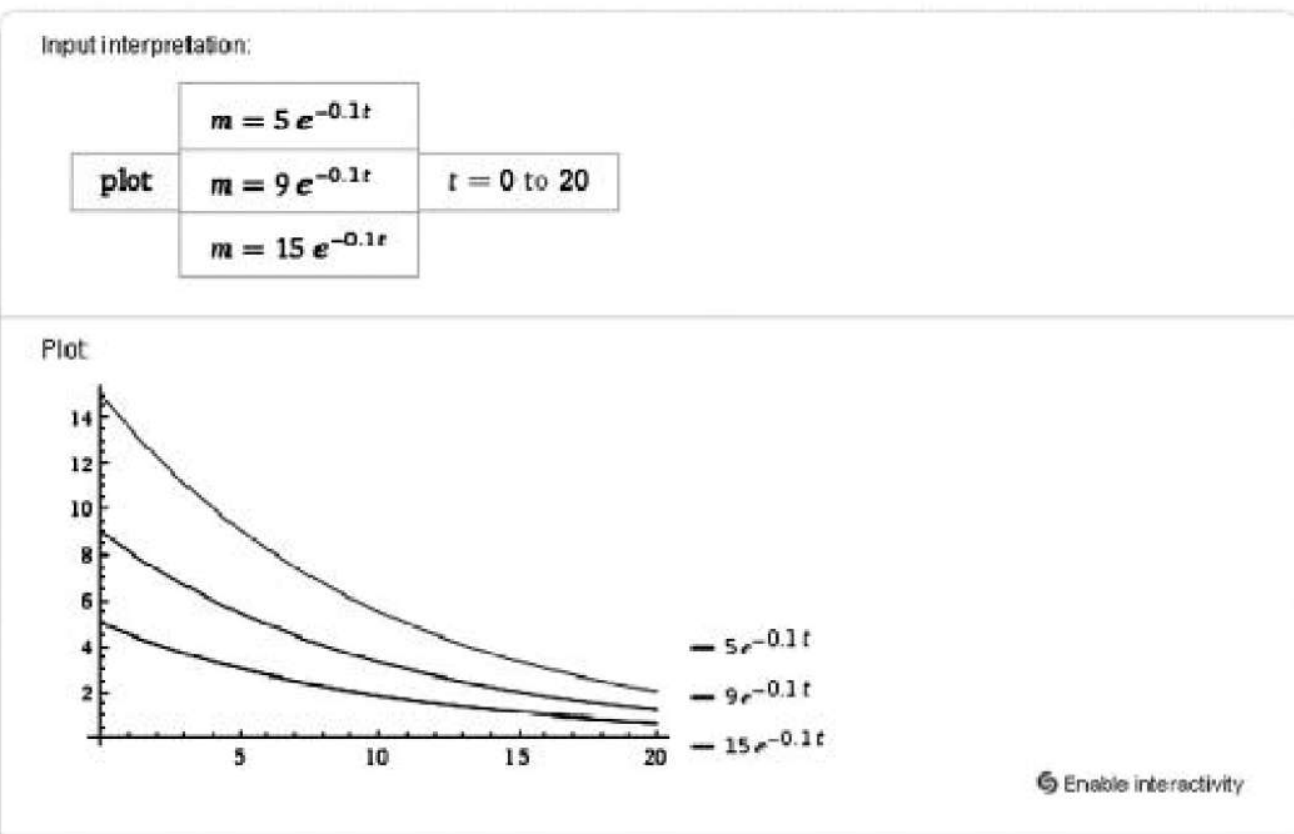

Puc. 3. Графічні залежності кількості введених лікарських препаратів від часу для моделі одноразового введення препарату в орган. 
від локальних помилок, і користувач повинен пам'ятати про способи контролю проведених обчислень. Тобто потрібно, в певному сенсі, вміти відслідковувати процес виконання перетворень та знати способи подання даних в WolframAlpha.

Головним недоліком даного ресурсу можна вважати відсутність редактора формул, необхідно знати певні команди та вміти ними користуватися для того, щоб виконати потрібну дію. Також існує два обмеження щодо використання WolframAlpha: поперше, необхідне підключення до інтернету, для того, щоб працювати; по-друге, на сьогодні немає WolframAlpha на яких-небудь інших мовах, крім англійської. Оскільки неправильні відповіді трапляються, то необхідно перевіряти кожну з них.

У викладацькому середовищі математиків існує обгрунтоване побоювання, що використання

\section{Література}

1. Бас С. В. WolframAlpha: можливості застосування у навчанні вищої математики студентів економічних спеціальностей / С. В. Бас // Наукові записки. Серія : проблеми методики фізико-математичної і технологічної освіти. Кіровоград : КДПУ 2013. - Вип. 2. - С. 8-11.

2. Гудирева О. М. Впровадження інформаційно-комунікативних технологій у навчальному процесі вищого навчального закладу / О. М. Гудирева // Інформаційні технології в освіті : зб. наук. праць. - Херсон : ХДУ 2010. Вип. 6. - С. 101-112.

3. Жалдак М. I. Педагогічний потенціал комп'ютерноорієнтованих систем навчання математики / М. І. Жалдак// Комп'ютерно-орієнтовані системи навчання : зб. наук. праць - К. : НПУ ім. М. П. Драгоманова, 2003. - Вип. 7. C. 3-16.

4. Клочко В. І. Комп'ютерно-орієнтована методика узагальнення і систематизації знань та вмінь в процесі навчання студентів аналітичної геометрії : монографія / Міністерство освіти та науки України ; Вінницький національний технічний університет ; В. І. Клочко, М. Б. Ковальчук. - Вінниця : ВНТУ 2009. - 116 с.
WolframAlpha "зіпсує" математичну підготовку студентів, подібно до того, як "калькулятор розучив їх рахувати". Вихід бачиться у роз'ясненні призначення та використання WolframAlpha. Очевидно, що успішне використання даного ресурсу можливе лише за умови знання основ математики.

Висновок. Зважуючи перелічені переваги та недоліки вважаємо, що використання WolframAlpha при вивченні вищої математики та комп'ютерних технологій у фармації у ВНЗ фармацевтичного профілю є обгрунтованим та дозволяє майбутнім фармацевтам отримати ряд навиків з подальшим застосуванням у практичній фармації, а саме коректно формулювати прикладну задачу, перекладати цю задачу на мову математики, розв'язувати за допомогою відповідного програмного пакету та інтерпретувати результат їі розв'язку на реальну ситуацію.

5. Семенець А. В. Концепція побудови інформаційної інфраструктури медичного ВНЗ з використанням вільнорозповсюджуваного програмного забезпечення з відкритим кодом / А. В. Семенець, В. Ю. Ковалок // Інформаційні технології і засоби навчання. - 2014. - № 3. - С. 277-288. 6. Семенець А. В. Застосування хмарних технологій при побудові інформаційної інфраструктури медичного ВНЗ / А. В. Семенець // Медична освіта. - 2014. - № 1. - С. 99104.

7. Марценюк В. П. Медична інформатика. Методи системного аналізу : навч. посібн. [для студ. вищ. мед. навч. закл.] / В. П. Марценюк, Н. О. Кравець. - Тернопіль : Укрмедкнига, 2002. - 177 с.

8. Методи системного аналізу медико-біологічних та фармакокінетичних процесів / В. П. Марценюк, Д. В. Вакуленко, А. С. Сверстюк, I. Є. Андрущак// XVI International conference «Problems of decision making under uncertainties (PDMU-2010)», (October 4-8), Abstracts, Kyiv, Ukraine, 2010. - P. 97-98. 